Japanese Journal of Physiology, 37, 1061-1065, 1987

\title{
Sodium Permeability of the Frog Tongue Epithelium
}

\author{
Hiroyuki SoEda and Fujio SAKudo \\ Department of Physiology, Fukuoka Dental College, \\ Sawara-ku, Fukuoka, 814-01 Japan
}

\begin{abstract}
Summary Application of $\mathrm{NaCl}$ to the frog tongue produced a sodium influx through the dorsal epithelium. The flux was distinctly faster through those of the palatal epithelium and the skin, and may influence taste reception in frogs.
\end{abstract}

Key words: Na permeability, tongue epithelium, relation to taste.

Stimulation of the isolated dorsal epithelium of the tongue with a hypertonic $\mathrm{NaCl}$ solution produces a slow change in transepithelial potential difference, associated with a decrease in tissue resistance in the dog (DESIMONE et al., 1984) and the frog (SoEda and SAKudo, 1985). These findings suggest that the tissue is permeable to some ions responsible for the response. However, in the prevailing view of the gustatory mechanism, the dorsal epithelium has been assumed to be a tissue of low permeability to most substances including small ions (BEIDLER, 1965; Mistretta, 1971; Sato and Beidler, 1975). Therefore, the sodium permeability of the dorsal epithelium in frog tongue during an application of $\mathrm{NaCl}$ was examined to determine some factors involved in taste reception.

The dorsal epithelium of bullfrog tongue (Rana catesbeiana) was dissected free from the underlying muscle. The tissue was mounted symmetrically between 2 plastic plates to separate the mucosal surface and the opposite surface usually called the serosal one (each $1 \mathrm{~cm}^{2}$ ) as described elsewhere (SOEDA and SAKUdO, 1985). Both surfaces were previously perfused with a normotonic sucrose solution ( $224 \mathrm{~mm}$ ), and all ions of the tissue surfaces were replaced with it; $\mathrm{NaCl}$ was continuously added to the sucrose solution in the mucosa, and the serosal solution was collected every $10 \mathrm{~min}$. The amount of sodium permeated into the serosal solution was measured using a flame photometer. Edge damage with apparatus was not considered to occur, since the resistance of the tissue mounted on the apparatus under Ringer solution $\left(710 \pm 180 \Omega / \mathrm{cm}^{2}\right)$ was considerably high (SOEDA and SAKudo, 1985). The sucrose solution used was passed through deionizing resins to remove all ions. For perfusion of the solution, a circulating pump was used to keep the flow rate at

Received for publication September 28, 1987 
$3 \mathrm{ml} / \mathrm{min}$. Permeability of the dorsal epithelium was compared with those of the frog palatal epithelium and abdominal skin using the same procedure as above. The permeability constant ( $p$ ) was calculated according to MistretTA (1971): $p=r / c$ $(\mathrm{cm} / \mathrm{min})$, where $r$ is the rate of sodium permeation and $c$ is the difference in sodium concentration on the two sides of the tissue. In this study, $c$ is equal to the $\mathrm{NaCl}$ concentration added to the mucosal solution, because the serosal solution was the sucrose solution alone constantly perfused.

After both surfaces of the tissue started to be perfused with the sucrose solution, the sodium concentration in the mucosal solution rapidly decreased within the initial $15 \mathrm{~min}$, followed by a gradual decrease and reached zero at about $60 \mathrm{~min}$. A similar decrease was observed in the serosa, but it took 90 min to reach zero. All 13 specimens examined showed similar time courses.

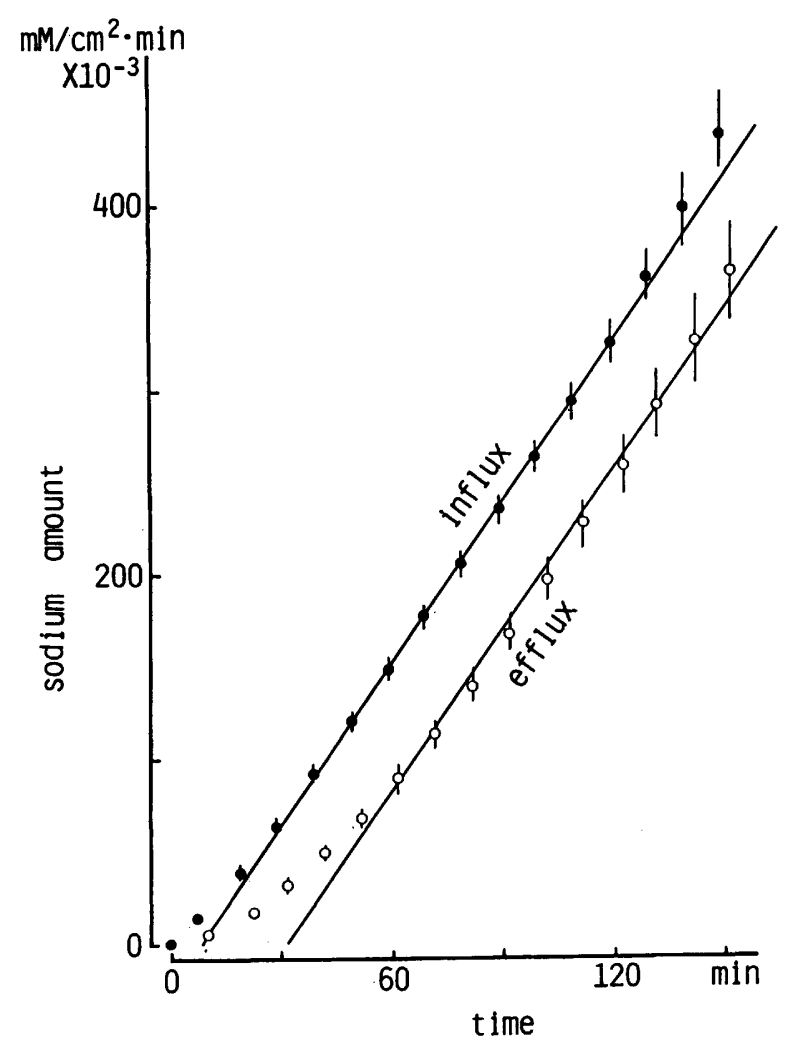

Fig. 1. Summated amounts of sodium influx and efflux through the isolated dorsal epithelium from frog tongue during continuous addition of $0.1 \mathrm{M} \mathrm{NaCl}$ to the sucrose solution on the mucosal or the serosal surface. Abscissa indicates the time after the $\mathrm{NaCl}$ application. Straight line in each curve shows the maximum rate of permeation. Each plot and vertical bar represent the mean value and its S.E. obtained from 5 to 7 tissues. 
Application of $0.05-0.2 \mathrm{M} \mathrm{NaCl}$ to the mucosa produced a sodium influx through the tissue to the serosa. The rate of the influx was dependent upon the $\mathrm{NaCl}$ concentration applied. Efflux similar to the influx was also observed when $0.1 \mathrm{M}$ $\mathrm{NaCl}$ was applied to the serosa. Figure 1 shows a comparison between the influx and the efflux during the $0.1 \mathrm{M} \mathrm{NaCl}$ application. The curves represent the summated amount of flux; the slope of each straight line therefore indicates the rate of the sodium flux. By extrapolating from the straight-line portion of the curve to the abscissa, a delay time is obtained. The maximum rates of both sodium fluxes are equal to each other, but the delay time is shorter for the influx than for the efflux. The permeability constant and the delay time with $0.1 \mathrm{M} \mathrm{NaCl}$ application averaged from 5 to 7 tissues were $31.5 \pm 3.5 \times 10^{-3} \mathrm{~cm} / \mathrm{min}$ and $10.5 \pm 3.0 \mathrm{~min}$ in the influx, and $31.3 \pm 2.4 \times 10^{-3} \mathrm{~cm} / \mathrm{min}$ and $34.7 \pm 4.5 \mathrm{~min}$ in the efflux, respectively. These permeability constants are approximately three orders faster than those of nonelectrolytes through the rat tongue epithelium (MISTRETTA, 1971), and suggest that the frog dorsal epithelium permits the sodium permeation from either the mucosa to the serosa or vice versa. However, within around 40 min after the $\mathrm{NaCl}$ application, the permeation was faster in the former than in the latter.

The rate of sodium influx with $0.1 \mathrm{M} \mathrm{NaCl}$ was suppressed in the presence of $0.01-0.05 \%$ tetracaine on the mucosa. On the average, the permeability constant was decreased to $77.5,45.4$, and $23.2 \%$ by $0.01,0.02$, and $0.05 \%$ tetracaine application, respectively. These results coincide with that of the trans epithelial resporse across the tissue (SOEDA and SAKUDO, 1985), and suggest that the influx is not simply a physicochemical diffusion.

Potassium and lithium influxes were also examined when their $0.1 \mathrm{M}$ chloride solutions were respectively applied to the mucosa. The permeability constant and the delay time obtained from 3 to 7 tissues were $30.3 \pm 15.6 \times 10^{-3} \mathrm{~cm} / \mathrm{min}$ and $12.0 \pm 8.5 \mathrm{~min}$ for potassium and $9.6 \pm 0.1 \times 10^{-3} \mathrm{~cm} / \mathrm{min}$ and $21.5 \pm 0.5 \mathrm{~min}$ for lithium, respectively. Thus, the potassium influx was nearly equal to the above sodium influx, but the lithium influx was smaller and slower. Such a difference in permeabilities resembles the difference in the transepithelial response (SOEDA et al., 1985), and it may be due to an inherent hydrated ion size in aqueous solution as has been shown in cell membranes (GIESE, 1962).

The rate of sodium influx through the dorsal epithelium was distinctly faster than that through the frog palatal epithelium or skin (Fig. 2). As the figure clearly shows, the rate of sodium permeation through the tissue is related to the delay time: the slow permeation showed a long delay time, as has been demonstrated in the permeation of non-electrolytes through the rat tongue epithelium (MistretTA, 1971). The permeability constant and the delay time were $11.0 \pm 1.7 \times 10^{-3} \mathrm{~cm} / \mathrm{min}$ and $34.0 \pm 6.0 \mathrm{~min}$ in the palatal epithelium, and $0.7 \pm 0.4 \times 10^{-3} \mathrm{~cm} / \mathrm{min}$ and $56.0 \pm 10.0 \mathrm{~min}$ in the skin, respectively.

It is accepted that the stratum corneum is the principal permeation barrier in the skin (Scheuplein and Blank, 1971). Even cursory examinations of the histological section show that the dorsal surface of the frog tongue is not covered 


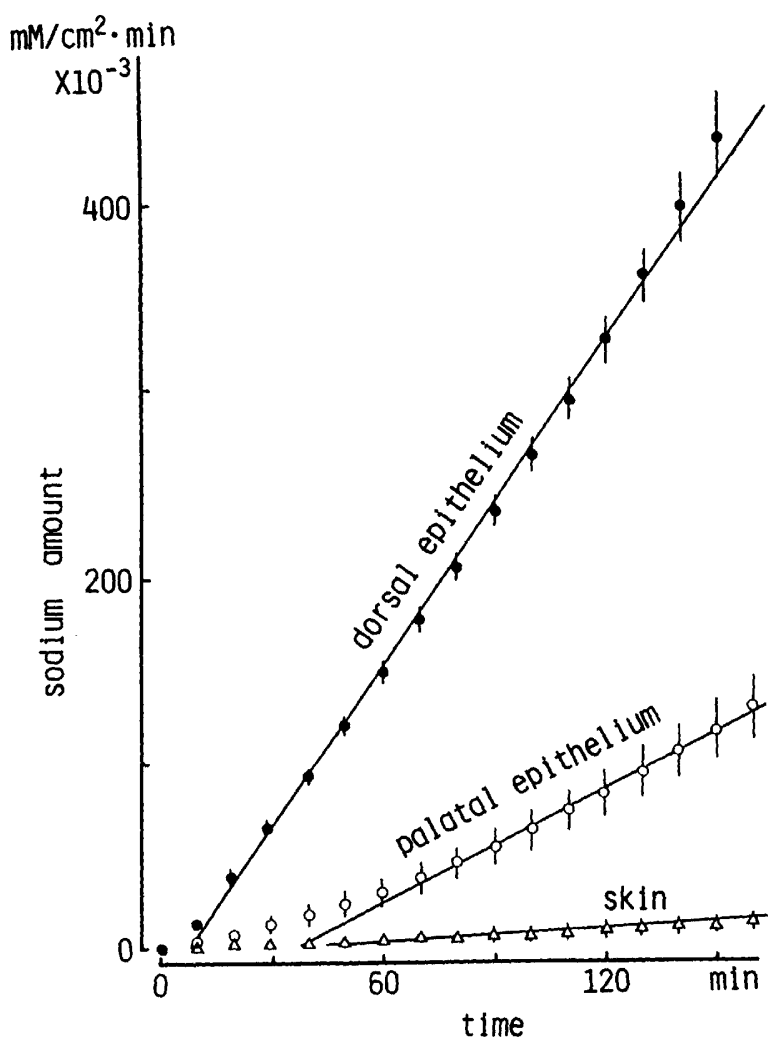

Fig. 2. Comparison of summated sodium influx through the dorsal epithelium with those through the palatal epithelium and the skin in frogs when $0.1 \mathrm{M} \mathrm{NaCl}$ was continuously added to the mucosa. Each curve was derived from 4 to 5 tissues.

with a keratinized layer (SOEDA and SAKUDO, 1985), while that of rat tongue is (MrstretTA, 1971). In fact, the dorsal surface of the frog tongue is flabby to the touch compared with the rat tongue. Therefore, the sodium permeability of the frog tongue epithelium may be larger than that of the rat tongue epithelium. The difference in sodium permeability among the dorsal epithelium and other tissues in frogs can also be expected to be related to their histological structures. VouTE (1963) reported that the frog skin consists of a thin cornified layer overlying the stratified squamous epithelium.

Frizzell and Schultz (1972) showed that a majority of the transmural conductances across the rabbit ileum can be attributed to the extracellular pathway implicating the transmural potential difference, and the pathway is cation selective. Also, the inward current through the rat tongue epithelium and the neural response caused by $\mathrm{NaCl}$ can be substantially reduced by the sodium blocker, amiloride (HECK et al., 1984). These are favorable to our findings and also to the transepithelial response to $\mathrm{NaCl}$ we reported previously (SOEDA and SAKudo, 1985). The 
response was produced by the mucosal stimulation of $50 \mathrm{~s}$, and its profile was in many respects similar to that of the receptor potential in taste cells and to the taste nerve response (SATO and BEIDLER, 1975; SOEDA et al., 1985). On the other hand, no response was elicited by the serosal stimulation. There is as yet no conclusive evidence to explain the relation between the sodium influx and the response. Since the delay time was shorter in the influx than in the efflux (Fig. 1), the response may be produced at an immediate mucosal surface of the tissue. The permeability before a steady rate of each flux may be due to the time required for sodium permeation through some pathway of thick tissue. Thus, the sodium influx produces the response across the tissue including the taste organs and affects the receptor potential in a large number of taste cells. This may influence taste reception.

\section{REFERENCES}

BeIDLER, L. M. (1965) Comparison of gustatory receptors, olfactory receptors, and free nerve endings. Cold Spring Harbor Symp. Quant. Biol., 30: 191-200.

DeSimone, J. A., Heck, G. L., Mierson, S., and DeSimone, S. K. (1984) The active ion transport properties of canine lingual epithelia in vitro. J. Gen. Physiol., 83: 633-656.

Frizzell, R. A. and Schultz, S. G. (1972) Ionic conductances of extracellular shunt pathway in rabbit ileum. J. Gen. Physiol., 59: 318-346.

Giese, A. C. (1962) Cell Physiology, 2nd ed., W. B. Saunders Comp., Philadelphia and London, Chap. 12, pp. 223-243.

Heck, G. L., Mierson, S., and DeSimone, J. A. (1984) Salt taste transduction occurs through an amiloride-sensitive sodium transport pathway. Science, 223: 403-405.

Mistretta, C. M. (1971) Permeability of tongue epithelium and its relation to taste. Am. J. Physiol., 220: 1162-1167.

SATo, T. and BeIDLER, L. M. (1975) Membrane resistance change of the frog taste cells in response to water and $\mathrm{NaCl}$. J. Gen. Physiol., 66: 735-763.

Scheuplein, R. J. and Blank, I. H. (1971) Permeability of the skin. Physiol. Rev., 51, $702-747$.

Soeda, H. and SaKudo, F. (1985) Characteristics of the transepithelial potential change produced by $\mathrm{NaCl}$ in bullfrog tongue. Comp. Biochem. Physiol., 82A: 361-366.

Soeda, H., Sakudo, F., and Noda, K. (1985) Relation between translingual potential changes induced by $\mathrm{NaCl}$ in the bullfrog tongue and taste nerve activity. Jpn. J. Physiol., 35: 1101-1105.

Voute, C. L. (1963) An electron microscopic study of the skin of the frog. J. Ultrastruct. Res., 9: 497-510. 